\title{
Relevance of reactive oxygen species in liver disease observed in transgenic mice expressing the hepatitis $B$ virus $X$ protein
}

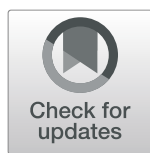

Dae-Yeul Yu(D

\begin{abstract}
The hepatitis B virus (HBV) infects approximately 240 million people worldwide, causing chronic liver disease (CLD) and liver cancer. Although numerous studies have been performed to date, unfortunately there is no conclusive drug or treatment for HBV induced liver disease. The hepatitis $B$ virus $X(\mathrm{HBX})$ is considered a key player in inducing CLD and hepatocellular carcinoma (HCC). We generated transgenic (Tg) mice expressing HBx protein, inducing HCC at the age of 11-18 months. The incidence of histological phenotype, including liver tumor, differed depending on the genetic background of HBx Tg mice. Fatty change and tumor generation were observed much earlier in livers of HBx Tg hybrid (C57BL/6 and CBA) (HBx-Tg hybrid) mice than in HBx Tg C57BL/6 (HBx-Tg B6) mice. Inflammation was also enhanced in the HBx-Tg B6 mice as compared to HBx-Tg hybrid mice. HBx may be involved in inducing and promoting hepatic steatosis, glycemia, hepatic fibrosis, and liver cancer. Reactive oxygen species (ROS) generation was remarkably increased in livers of $\mathrm{HBx}$ Tg young mice compared to young wild type control mice. Previous studies on $\mathrm{HBx} \mathrm{Tg}$ mice indicate that the HBx-induced ROS plays a role in inducing and promoting CLD and HCC.
\end{abstract}

Keywords: Hepatitis B virus (HBV), Hepatitis B virus X (HBX), Hepatocellular carcinoma (HCC), Hepatic steatosis, Hepatic fibrosis, Hepatic glucose, Reactive oxygen species (ROS), Oxidative stress, Transgenic mice

\section{Introduction}

The hepatitis B virus (HBV) infection is prevalent worldwide, causing liver disease and liver cancer. HBV, a member of the Hepadnaviridae family, is a small DNA virus similar to retrovirus [1]. The viral genome encodes four known genes: $\mathrm{C}, \mathrm{X}, \mathrm{P}$, and $\mathrm{S}$. The core protein is coded for by gene $\mathrm{C}$ ( $\mathrm{HBcAg}$ and $\mathrm{HBeAg})$, depending on whether translation initiates from the core or pre-core regions, respectively [2]. The $S$ gene encodes the viral surface envelope proteins (HBsAg), and can be structurally and functionally divided into the pre-S1, pre-S2, and $\mathrm{S}$ regions. The $\mathrm{P}$ gene encodes the large polymerase protein (pol; about 800 amino acids). The HBV X ( $\mathrm{HBx})$ gene encodes a 16.5 -kd protein $(\mathrm{HBxAg})$ having multiple functions, including signal transduction, transcriptional activation, DNA repair, cell cycle control, and inhibition of protein degradation [3-6].

\section{Correspondence: dyyu10@kribb.re.kr}

Korea Research Institute of Bioscience and Biotechnology (KRIBB), 125 Gwahak-ro, Yuseong-gu, Daejeon 305-806, South Korea
Persistently high levels of HBV replication are suggested to be correlated with the progression of chronic liver disease (CLD) to hepatocellular carcinoma (HCC) [7]. A correlation between virus replication and CLD may, therefore, contribute to determining disease progression. Briefly, fragments of HBV DNA, mostly encoding the $\mathrm{HBx}$, become integrated at multiple sites within the host DNA [8]. These integration events result in enhancing the intrahepatic expression levels of HBx that alter patterns of host gene expression. Although the relatively low levels of $\mathrm{HBx}$ derived from the virus minichromosome support expression and replication of the virus gene, it was hypothesized that increase of intrahepatic levels of $\mathrm{HBx}$ epigenetically alters the expression patterns of selected host genes, contributing to both virus persistence and malignant transformation $[9,10]$. Recently it is reported that nuclear HBx binds the HBV minichromosome and modifies the epigenetic regulation of the covalently closed circular DNA (cccDNA) function [11] and HBx protein contributes to liver carcinogenesis

(C) The Author(s). 2020 Open Access This article is distributed under the terms of the Creative Commons Attribution 4.0 International License (http://creativecommons.org/licenses/by/4.0/), which permits unrestricted use, distribution, and 
by H3K4me3 modification through stabilizing WD repeat domain 5 protein [12]. Therefore, inhibition of HBV transcription from cccDNA is indicated to be a therapeutic target towarding a functional $\mathrm{HBV}$ cure.

In patients infected with $\mathrm{HBV}, \mathrm{HBx}$ often co-exists with $\mathrm{HBe}$ in serum [13] and as replication complexes (with $\mathrm{HBcAg}$ ) in the liver [14]. HBxAg was present most often in sera positive for HBeAg and/or HBV DNA or apparently complexed to anti-HBx in sera lacking these markers [13]. HBx is required to initiate and maintain HBV replication in HepaRG cells [15] and human-liverchimeric mice [16]. Thus, HBx expression is associated with virus replication. In connection with the fact that $\mathrm{HBx}$ plays a key role in HBV replication, the expression and activity of $\mathrm{HBx}$ is stimulated in an oxidative environment. An oxidative environment could be created in HBV infected cells by virtue of the association of $\mathrm{HBx}$ with mitochondria [17]. Oxidative stress induced by $\mathrm{HBx}$ in the endoplasmic reticulum activates the unfolded protein response and expression of pro-inflammatory cyclooxygenase- 2 through the activation of transcription factor 4 pathway [18]. In addition, oxidative stress induced by mitochondrial associated $\mathrm{HBx}$ activates selected transcription factors, such as NF-kB, STAT3 and activating protein 1 [19].

Reactive oxygen species (ROS) are derived from the metabolism of molecular oxygen [20], and include the superoxide anion radical $\left(\mathrm{O}_{2}^{-}\right)$, singlet oxygen $\left({ }^{1} \mathrm{O}_{2}\right)$, hydrogen peroxide $\left(\mathrm{H}_{2} \mathrm{O}_{2}\right)$, and the highly reactive hydroxyl radical $(\cdot \mathrm{OH})$. The harmful effects of oxygen emanate from its metabolic reduction to these highly reactive and toxic species [19]. ROS normally exist in all aerobic cells balanced with biochemical antioxidants. Oxidative stress occurs when this critical balance is disrupted due to excess ROS, antioxidant depletion, or both. Given that ROS production is a natural process, and that persistently high levels of ROS could be damaging, the human body has developed antioxidant systems for their neutralization. Various enzymatic and non-enzymatic mechanisms have evolved to protect cells against ROS. Enzymatic antioxidants include superoxide dismutase (SOD, which detoxifies the superoxide ion), and catalase, glutathione peroxidase (GPx) and peroxiredoxins (Prxs), which inactivate $\mathrm{H}_{2} \mathrm{O}_{2}$. All Prx enzymes contain a conserved cysteine (Cys) residue that undergoes a cycle of peroxide-dependent oxidation and thiol-dependent reduction during catalysis. There are 6 isoforms of Prx (Prx I to VI) in mammalian cells, which are classified into 3 subgroups (2-Cys, atypical 2-Cys, and 1 -Cys) based on the number and position of Cys residues that participate in catalysis [21]. Several researches have reported that Prxs are associated with CLD [22-24].

A correlation between $\mathrm{HBx}$ staining and the intensity of CLD is expected in this chronic pro-inflammatory environment. Relatively low levels of intrahepatic $\mathrm{HBx}$ staining were found in biopsy samples from patients with low grade hepatitis, whereas intense and widespread HBx staining has been observed in biopsies from advanced fibrosis and cirrhosis $[9,25]$, indicating a direct correlation between $\mathrm{HBx}$ staining and liver damage. The relationship of $\mathrm{HBx}$ expression to disease severity is also consistent with the idea that when the liver regenerates, fragments of $\mathrm{HBV}$ DNA encoding the $\mathrm{HBx}$ region increasingly integrate into multiple regions of the host genome during normal host DNA replication, resulting in increasing accumulation of intrahepatic $\mathrm{HBx}$ with CLD progression [26]. Thus, persistent inflammation in a chronically damaged liver may result in the development of HCC, despite low levels or undetectable levels of virus replication [26].

\section{Main text}

\section{Generation of $\mathrm{HBx} \mathrm{Tg}$ mice inducing liver cancer}

Until the 1990's, chronic infection with HBV was regarded as one of the major causes of HCC. However, there was no evidence to prove that the HBV gene is involved in tumor development. In 1987, through identification of a viral regulatory gene $\mathrm{HBx}$, the virus was suggested to be directly involved in HCC. The HBx protein alters the host gene expression and results in the development of $\mathrm{HCC}$ by acting as a transcriptional transactivator of viral genes [27]. Therefore, transgenic ( $\mathrm{Tg})$ mice expressing HBx were generated in several laboratories to prove whether $\mathrm{HBx}$ may play a key role in inducing HCC. Kim et al. [28] reported that HBx induces liver cancer in Tg mice. A high incidence of HCC was found in $\mathrm{Tg}$ mice, subsequent to microinjecting a $1.15 \mathrm{~kb}$ HBV subtype $a d r$ DNA fragment with nucleotide positions 707 to 1856 in the viral genome. In contrast, the HBx Tg mice generated in other laboratories developed no obvious hepatic pathology, although they expressed the X-gene in liver cells and the HBx protein could be detected in some cases [29-32]. Therefore, $\mathrm{HBx}$ was concerened with an oncogenic role. We demonstrated to generate $\mathrm{HBx} \mathrm{Tg}$ mice to confirm whether $\mathrm{HBx}$ induces liver cancer [33]. The X-gene construct with an HBV-X gene under authentic promoter was microinjected into hybrid (C57BL/6 x DBA) eggs. We consistently observed grossly defined HCC in mice expressing the $\mathrm{X}$-protein through 6 generations, from the ages of 11 to 18 months. The incidence of HCC (86\%) in our HBx Tg mice may be highly significant, since the HBV X-gene Tg mice produced in other laboratories did not develop liver tumor or any other pathologic phenomena, except for one case [28]. Since then, $\mathrm{Wu}$ et al. have generated $\mathrm{HBx} \mathrm{Tg}$ mice to investigate in vivo effects of $\mathrm{HBx}$ on hepatocyte proliferation and viability during liver regeneration of the $\mathrm{HBx} \mathrm{Tg}$ mice post-hepatectomy [34]. They injected the albumin 
HBx construct into embryos of C57BL/6 mice, and succeeded in generating $\mathrm{HBx} \mathrm{Tg}$ mice that developed $\mathrm{HCC}$ at around 14-16 months of age. Wang et al. also introduced the HBx gene into the p21 locus of the mouse genome by homologous recombination, to better understand the consequences of integrating the HBV gene [35]. The $\mathrm{HBx}$ gene knock-in Tg mice expressed $\mathrm{HBx}$ mainly in the liver tissues, and developed HCC.

As mentioned above, $\mathrm{HBx} \mathrm{Tg}$ mice have been generated in eight laboratories till date (Table 1). Of these, four laboratories succeeded in generating $\mathrm{HBx} \mathrm{Tg}$ mice inducing $\mathrm{HCC}$, which did not develop in the other 4 laboratories. Although HCC was caused in all bitransgenic animals derived by crossing $\mathrm{HBx} \mathrm{Tg}$ mice with WHV/c-myc oncomice in which liver specific expression of c-myc was driven by woodchuck hepatitis virus (WHV) regulatory sequences [36].

It is difficult to understand why four laboratories failed to observe $\mathrm{HCC}$ in their $\mathrm{HBx} \mathrm{Tg}$ mice. Although certain factors, mouse strain, HBV genotype and HBx integration site were considered to be responsible, it is difficult to deduce which factor is involved in achieving success or failure of inducing $\mathrm{HCC}$ in $\mathrm{HBx} \mathrm{Tg}$ mice. This is because the same mouse strain and HBV genotype were cross-used in generating $\mathrm{HBx}$ tg mice, and HBx integration site was not identified in all $\mathrm{HBx} \mathrm{Tg}$ mice. However, considering all results, it is apparent that $\mathrm{HBx}$ has an oncogenic role in hepatic tumorigensis in $\mathrm{Tg}$ mice.

\section{Difference between hepatic phenotypes, depending on the HBx Tg mouse strains}

As previously mentioned [33], $\mathrm{HBx} \mathrm{Tg}$ mouse was generated using the $\mathrm{F} 1$ hybrid mouse strain (C57BL/6 X DBA), since hybrid embryos are harder than inbred embryos and microinjection of $\mathrm{HBx}$ transgene into embryos is easier. After confirming that $\mathrm{HBx} \mathrm{Tg}$ mice induced $\mathrm{HCC}$, we generated $\mathrm{HBx}$ homozygous $\mathrm{Tg}$ mice $\left(\mathrm{HBx}^{+/+} \mathrm{Tg}\right)$ using the strains $\mathrm{C} 57 \mathrm{BL} / 6$, hybrid $(\mathrm{C} 57 \mathrm{BL} / 6$ $\mathrm{X}$ CBA), and CBA, to understand the phenotypes depending on their genetic background. Compared to wild type (WT) mice, the body weight significantly increased from about 6 weeks of age to old age in the $\mathrm{HBx} \mathrm{Tg}$ mice regardless of strain, suggesting that $\mathrm{HBx}$ expression in hepatocytes induces increase in body weight as compared to WT. HBx Tg hybrid (C57BL/6 X CBA) (HBxTg hybrid) mice show about 2-3-fold increased body weight than the $\mathrm{HBx} \mathrm{Tg} \mathrm{C} 57 \mathrm{BL} / 6$ (HBx-Tg B6) mice. In addition, $\mathrm{HBx}-\mathrm{Tg}$ hybrid mice were larger in size than $\mathrm{HBx}-\mathrm{Tg} \mathrm{B} 6$ mice. However, a sufficient number of $\mathrm{HBx}-$ Tg CBA mice were not obtained to examine the phenotype due to difficulty of breeding the mice, resulting in no data on $\mathrm{HBx}$-Tg CBA mice. We could only determine that the size of $\mathrm{HBx}-\mathrm{Tg}$ CBA mice is similar to $\mathrm{HBx}-\mathrm{Tg}$ hybrid mice.

Assessment of the histological phenotype revealed features associated with hepatic tumorigenesis in liver of WT and HBx Tg mice (Tables 2,3). Fatty change appeared in HBx Tg mouse livers, but not in WT mouse livers. Especially, micro-fatty changes were observed in $31.9 \%$ of $\mathrm{HBx}-\mathrm{Tg}$ hybrid mice at the age of $\sim 12$ weeks, but were absent in WT mice at the same age. Moreover, micro-fatty changes appeared in $6.7 \%$ of $\mathrm{HBx}-\mathrm{Tg} \mathrm{B} 6$ mice, but not in WT mice at the same age. However, macro-fatty changes were observed in $4.3 \%$ of $\mathrm{HBx}-\mathrm{Tg}$ hybrid mice, but not in WT and HBx-Tg B6 mice at the same age. Fatty change was observed in all $\mathrm{HBx}-\mathrm{Tg} \mathrm{B} 6$ mice at the age of $28 \sim 44$ weeks, and in all $\mathrm{HBx}-\mathrm{Tg}$ hybrid mice at the age of $28 \sim 36$ weeks. These data suggest that the greater body weight of $\mathrm{HBx}-\mathrm{Tg}$ hybrid mice than HBx-Tg B6 mice may be associated with the increased fatty changes observed in $\mathrm{HBx}$ - Tg hybrid livers in young mice. Inflammation was observed in the livers of $9.8 \sim 50 \% \mathrm{HBx} \mathrm{Tg}$ mice examined, and was observed to be augmented in $\mathrm{HBx}-\mathrm{Tg} \mathrm{B} 6$ mice as compared to $\mathrm{HBx}-\mathrm{Tg}$ hybrid mice. Inflammation was detected in 22.2\% $\mathrm{HBx}-\mathrm{Tg} \mathrm{B} 6$ mice and in 17\% $\mathrm{HBx}-\mathrm{Tg}$ hybrid mice at the age of $\sim 12$ weeks, but not in WT mice at the same age. These data also suggest that HBx induces inflammation in the livers of $\mathrm{HBx} \mathrm{Tg}$ mice. However, the rate differs in accordance with the strain and age of $\mathrm{HBx}$ $\mathrm{Tg}$ mice. Necrosis was almost absent in the livers of $\mathrm{HBx}-\mathrm{Tg}$ hybrid mice, but minimally detected in the

Table $1 \mathrm{HBx}$ transgenic mice published

\begin{tabular}{lllll}
\hline HBV DNA subtype & Promoter & Mouse strain & Tumor generation & Published paper \\
\hline adr & HBV X & CD-1 & HCC & Kim et al. (Nature 1991) [28] \\
adr & HBV X & F1 hybrid (C57BL/6 X DBA) & HCC & Yu et al. (J of Hepatology 1999) [33] \\
ayw & SV40, ATIII, HBV X & F1 hybrid (C57BL/6 X DBA) & No serious liver damage & BILLET et al. (J of Virology 1995) [29] \\
adw & Alpha1 antitrypsin & ICR females X B6C3F1 males. & No tumor & Lee et al. (J of Virology 1990) \\
ayw & HBV X & F1 hybrid (C57BL/6 X DBA) & No description & Perfumo et al. (J of Virology 1992) [31] \\
No description & HBV X, Rat insulin II & C57BL/6, F2 hybrid(C57BL/6 X DBA) & No pathological change & Reifenberg et al. (J of Hepatology 1997) [32] \\
ayw & albumin & C57BL/6 & HCC & Wu et al. (BBRC 2006) [34] \\
No description & HBV X in p21 locus & C57BL/6 & HCC & Wang et al. (Hepatology 2004) [35] \\
\hline
\end{tabular}


Table 2 The histological phenotype in the liver of wild and HBx-Tg B6 mice

\begin{tabular}{|c|c|c|c|c|c|c|}
\hline & \multicolumn{3}{|l|}{ Group 1} & \multicolumn{3}{|l|}{ Group 2} \\
\hline & WT & $\mathrm{HBx} \mathrm{Tg}$ & $P$-value & WT & $\mathrm{HBx} \mathrm{Tg}$ & $P$-value \\
\hline Micro-fatty change & 0/39(0\%) & $3 / 45(6.7 \%)$ & 0.101 & 9/47(19.1\%) & 40/51(78.4\%) & 0.000 \\
\hline Macro-fatty change & 0/39(0\%) & $0 / 45(0 \%)$ & - & $2 / 47(4.3 \%)$ & 25/51(49.0\%) & 0.045 \\
\hline Inflammation & 0/39(0\%) & 10/45(22.2\%) & 0.002 & 9/47(19.1\%) & $5 / 51(9.8 \%)$ & 0.187 \\
\hline Necrosis & 0/39(0\%) & $1 / 45(2.2 \%)$ & 0.349 & 0/47(0\%) & 4/51(7.8\%) & 0.050 \\
\hline Dysplasia & 0/39(0\%) & 43/45(95.6\%) & 0.000 & 0/47(0\%) & 48/51(94.1\%) & 0.000 \\
\hline Dysplastic nodule & 0/39(0\%) & $0 / 45(0 \%)$ & - & 0/47(0\%) & $1 / 51(2.0 \%)$ & 0.335 \\
\hline \multirow[t]{2}{*}{ Tumor } & 0/39(0\%) & 0/45(0\%) & - & 0/47(0\%) & 0/51(0\%) & - \\
\hline & \multicolumn{3}{|l|}{ Group 3} & \multicolumn{3}{|l|}{ Group 4} \\
\hline Micro-fatty change & 4/13(30.8\%) & 15/15(100\%) & 0.000 & 1/3(33.3\%) & $7 / 8(87.5 \%)$ & 0.072 \\
\hline Macro-fatty change & $0 / 13(0 \%)$ & 15/15(100\%) & 0.000 & 0/3(0\%) & 3/8(37.5\%) & 0.214 \\
\hline Inflammation & $1 / 13(7.7 \%)$ & $3 / 15(20.0 \%)$ & 0.353 & 1/3(33.3\%) & $4 / 8(50 \%)$ & 0.621 \\
\hline Necrosis & $1 / 13(7.7 \%)$ & $1 / 15(6.7 \%)$ & 0.916 & $0 / 3(0 \%)$ & $2 / 8(25.0 \%)$ & 0.338 \\
\hline Dysplasia & 0/13(0\%) & 15/15(100\%) & 0.000 & 0/3(0\%) & 8/8(100\%) & 0.001 \\
\hline Dysplastic nodule & 0/13(0\%) & $1 / 15(6.7 \%)$ & 0.343 & 0/3(0\%) & $5 / 8(62.5 \%)$ & 0.064 \\
\hline Tumor & 0/13(0\%) & 1/15(6.7\%) & 0.343 & 0/3(0\%) & $5 / 8(62.5 \%)$ & 0.064 \\
\hline
\end{tabular}

Group 1: 12 weeks, Group 2: 12 28 weeks

Group 3: 28 44 weeks, Group 4: 44 64 weeks

livers of $\mathrm{HBx}-\mathrm{Tg} \mathrm{B} 6$ mice. Regardless of the strain, dysplasia was observed in almost all $\mathrm{HBx} \mathrm{Tg}$ mice from a young age, suggesting that $\mathrm{HBx}$ is involved in abnormal growth of hepatocytes. Dysplastic nodules were found at 12 28 weeks age in $\mathrm{HBx}$-Tg hybrid mice; however, it was remarkably observed only in later stages of $\mathrm{HBx}-\mathrm{Tg}$ B6 mice (44 64 weeks age). Hepatic tumors were detected in $87.5 \% \mathrm{HBx}-\mathrm{Tg}$ hybrid mice at the age of 28 36 weeks, but were observed in 62.5\% HBx-Tg B6 mice at the advanced age of $44 \sim 64$ weeks. These results indicate that hepatic tumors develop earlier in the HBx$\mathrm{Tg}$ hybrids than in $\mathrm{HBx}-\mathrm{Tg} \mathrm{B} 6$ mice.

Taken together, the results indicate that fatty changes and tumor generation are observed much earlier in livers of the $\mathrm{HBx}-\mathrm{Tg}$ hybrid mice than in $\mathrm{HBx}-\mathrm{Tg} \mathrm{B} 6$ mice. Furthermore, the histological phenotypes associated with hepatic tumorigenesis are different, depending on the strain of $\mathrm{HBx} \mathrm{Tg}$ mice, suggesting that genetic backgrounds affect phenotypes of $\mathrm{HBx} \mathrm{Tg}$ mice.

\section{HBx induces hepatic steatosis in Tg mice}

It was suggested that chronic HBV infection is frequently associated with hepatic steatosis, which is a common histologic feature of chronic infection with hepatitis $\mathrm{C}$ virus (HCV) [37]. The frequency of hepatic steatosis ranges from 27 to $51 \%$ in subjects with a chronic HBV infection, and 31 to $72 \%$ in chronic $\mathrm{HCV}$ patients. Despite the high frequency of HBV-associated hepatic steatosis, the molecular mechanism of HBV or its viral proteins resulting in the pathogenesis of HBVassociated hepatic steatosis is unknown. We therefore

Table 3 The histological phenotype in the liver of wild and HBx-Tg hybrid mice

\begin{tabular}{|c|c|c|c|c|c|c|c|c|c|}
\hline & \multicolumn{3}{|l|}{ Group 1} & \multicolumn{3}{|l|}{ Group 2} & \multicolumn{3}{|l|}{ Group 3} \\
\hline & WT & $\mathrm{HBx} \mathrm{Tg}$ & $P$-value & WT & $\mathrm{HB} \times \mathrm{Tg}$ & $P$-value & WT & $\mathrm{HB} \times \mathrm{Tg}$ & $P$-value \\
\hline Micro-fatty change & 0/34(0\%) & 15/47 (31.9\%) & 0.001 & $1 / 6(16.7 \%)$ & 12/14 (85.7\%) & 0.003 & $5 / 9(55.6 \%)$ & $8 / 8(100 \%)$ & 0.031 \\
\hline Macro-fatty change & 0/34(0\%) & $2 / 47(4.3 \%)$ & 0.223 & $0 / 6(0 \%)$ & 4/14 (28.6\%) & 0.143 & 0/9 (0\%) & $8 / 8(100 \%)$ & 0.000 \\
\hline Inflammation & 0/34(0\%) & $8 / 47(17.0 \%)$ & 0.011 & 0/6 (0\%) & $1 / 14(7.1 \%)$ & 0.502 & 0/9 (0\%) & $1 / 8(12.5 \%)$ & 0.274 \\
\hline Necrosis & 0/34(0\%) & $1 / 47(2.2 \%)$ & 0.392 & $0 / 6(0 \%)$ & 0/14 (0\%) & - & $0 / 9(0 \%)$ & 0/8 (0\%) & - \\
\hline Dysplasia & 0/34(0\%) & 46/47 (97.9\%) & 0.000 & $0 / 6(0 \%)$ & 13/14 (92.9\%) & 0.000 & $0 / 9(0 \%)$ & $8 / 8(100 \%)$ & 0.001 \\
\hline Dysplastic nodule & 0/34(0\%) & 0/47 (0\%) & - & 0/6 (0\%) & 4/14 (28.6\%) & 0.143 & $0 / 9(0 \%)$ & $7 / 8(87.5 \%)$ & 0.000 \\
\hline Tumor & 0/34(0\%) & 0/47 (0\%) & - & 0/6 (0\%) & 2/1414.3\%) & 0.329 & 0/9 (0\%) & 7/8 (87.5\%) & 0.000 \\
\hline
\end{tabular}

Group 1: 12 weeks, Group 2: 12 28 weeks, Group 3: 28 36 weeks 
investigated whether $\mathrm{HBx}$ may be involved in hepatic steatosis in $\mathrm{HBx}-\mathrm{Tg}$ hybrid mice. As mentioned above, the body weight of $\mathrm{HBx} \mathrm{Tg}$ mice significantly increases from about 6 weeks age to old age regardless of strain, when compared to WT mice, suggesting that HBx expression in hepatocytes induces increased growth of body weight. In addition, the liver weight per body weight of $\mathrm{HBx}$-Tg hybrid mice increased 2-fold as compared with the WT mice at age 11-weeks. Moreover, H\&E staining revealed the presence of diffused intracellular lipid droplets in liver sections of $\mathrm{HBx}-\mathrm{Tg}$ hybrid mice. Increased lipid accumulation in livers of $\mathrm{HBx}-\mathrm{Tg}$ hybrid mice was also observed by Oil-Red O staining. In addition, $\mathrm{HBx}-\mathrm{Tg}$ hybrid mice show dysplasia as well as the fatty changes (Tables 2,3 ). These results obtained in $\mathrm{HBx}$-Tg hybrid mice, as well as lipid accumulation in HepG2 cells overexpressing $\mathrm{HBx}$, indicate that $\mathrm{HBx}$ plays a role in the development of hepatic steatosis [38]. Hepatic fatty change was also observed in $\mathrm{HBx} \mathrm{Tg}$ mice generated at other laboratories [34]. The molecular mechanism by which HBx causes lipid accumulation was therefore investigated and is summarized as follows. $\mathrm{HBx}$ leads to increased AKT activity and inhibition of PTEN expression, resulting in activation of sterol regulatory element binding protein 1 (SREBP1), which upregulates hepatic lipid synthesis. The enhancement of CEBP $\alpha$ expression and activity by $\mathrm{HBx}$ results in increased PPAR $\gamma$ activity, thereby inducing the expression of hepatic adipogenic genes [38]. The molecular mechanisms by which HBx increases SREBP1 expression and transactivation were elucidated [39]. HBx interacts with liver X receptor $\alpha(\mathrm{LXR} \alpha)$ and enhances the binding of LXR $\alpha$ to LXR-response element (LXRE), thereby resulting in the upregulation of SREBP1 and fatty acid synthesis (FAS) to support lipogenesis in hepatic cells and HBx-Tg hybrid mice. In addition, increased ROS production further contributes to increased lipid droplet formation in $\mathrm{HBx}$ expressing cells [40]. Wu et al. also reported that liver fatty acid binding protein (FABP1) is dramatically expressed in the sera of $\mathrm{HBV}$-infected patients and in both sera and liver tissues of $\mathrm{HBV} \mathrm{Tg}$ mice, and may play a role in $\mathrm{HBx}$-induced hepatic lipid accumulation via regulation of HNF3 $\beta, \mathrm{C} / \mathrm{EBP} \alpha$, and PPAR $\alpha$ in the development of HBV-induced nonalcoholic fatty liver disease [41]. However, PPAR $\alpha$ was not expressed in the HBx-Tg hybrid mice developed by us [38]. It is therefore necessary to confirm, in future studies, whether HNF3 $\beta$ and C/EBP $\alpha$ are involved in HBx induced hepatic lipid accumulation.

\section{$\mathrm{HBx}$ regulates hepatic glucose homeostasis in Tg mice} HBV infection is strongly associated with type 2 diabetes [42, 43], and diabetic hyperglycemia is associated with serum alanine aminotransferase activity in patients with HBV infection
[44]. Chronic infection of HCV also develops a pathological feature of steatohepatitis. Inflammatory mediators, such as nitric oxide and TNF- $\alpha$, have been shown to impair the metabolic action of insulin in the liver, which ultimately results in hepatic dysfunction causing insulin resistance. In fact, expression of inducible nitric oxide synthase (iNOS) is upregulated in the liver of chronic HBV-infected patients [45]. During acute or chronic HBV infection, HBx plays a key role in the induction of hepatic inflammatory responses, as proved by the fact that $\mathrm{HBx}$ transactivates the promoter of the iNOS gene through the proximal NF- $\mathrm{kB}$ binding site [46]. In addition, the HBV-induced TNF- $\alpha$ synthesis is transcriptionally up-regulated by $\mathrm{HBx}$ in hepatocytes [47]. However, the mechanisms through which HBV leads to glucose metabolism in chronic liver diseases were not elucidated. We therefore investigated the role of $\mathrm{HBx}$ in regulating glucose metabolism in $\mathrm{HBx}-\mathrm{Tg} \mathrm{B} 6$ mice and $\mathrm{HBx}-\mathrm{Tg} \mathrm{B} 6$ mice lacking iNOS. Livers of HBx-Tg B6 mice revealed increased expressions of gluconeogenic genes, similar to the HepG2 cells expressing $\mathrm{HBx}$ and non-tumor liver tissues of HBV patients with high expressions of $\mathrm{HBx}$. This resulted in hyperglycemia due to increased glucose production. Importantly, the actions of $\mathrm{HBx}$ on hepatic glucose metabolism were thought to be mediated via iNOS signaling, as evidenced by the restoration of $\mathrm{HBx}$-induced hyperglycemia, by suppressing the gene expression of gluconeogenic enzymes in iNOS knockout mice. Nitric oxide exposure of HepG2 cells expressing HBx caused a significant increase in the expression of gluconeogenic genes. Furthermore, hyperactivation of JNK1 in the liver of $\mathrm{HBx}-\mathrm{Tg} \mathrm{B} 6$ mice was also suppressed in the absence of iNOS, indicating the critical role of JNK in the mutual regulation of HBx- and iNOS-mediated glucose metabolism. These findings established a novel mechanism of $\mathrm{HBx}$-driven hepatic metabolic disorder modulated by iNOS-mediated activation of JNK [48]. It was also noted that the overexpression of $\mathrm{HBx}$ proteins enhances the promoter activity of PEPCK and G6Pase in HepG2 cells [49]. Furthermore, although insulin attenuates the expression of the PEPCK and G6Pase genes, HBx inhibited the insulin-induced suppression of the promoter activity of these genes. Moreover, $\mathrm{HBx}$ proteins augment the SOCS3 expression and decrease IRS1 proteins, thereby causing impairments of hepatic insulin signaling and inhibition of hepatic insulin action. Taken together, these results suggest that HBx impairs hepatic insulin signaling by decreasing IRS1 proteins and increasing SOCS3 expression, indicating that $\mathrm{HBx}$ regulates hepatic glucose homeostasis by suppressing insulin signaling.

\section{$\mathrm{HBx}$ enhances the development of liver fibrosis in $\mathrm{Tg}$ mice}

Liver fibrosis results from chronic damage to the liver, in conjunction with accumulation of extracellular matrix (ECM) proteins, including collagen [50]. Accumulation of ECM proteins induces fibrous scar 
formation, resulting in hepatic architecture distortion and subsequent regeneration of hepatocyte cirrhosis nodules. Moreover, cirrhosis brings about hepatocellular dysfunction and eventually progresses to liver cancer [51]. Chronic HBV infection induces liver fibrosis [52]. There are several convincing evidences that $\mathrm{HBx}$ correlates with the development of fibrosis. $\mathrm{HBx}$ induces severe lipid accumulation in $\mathrm{HBx}-\mathrm{Tg}$ hybrid mice [38], and alters the production of ECM by modulating the expression of membrane-type matrix metalloproteinase- 1 and fibronectin [53, 54]. More convincing evidence is the induction of liver fibrosis in HBV and HBx Tg mice exposed to carbon tetrachloride (CCl4) [55-57]. Gong et al. [57] reported that SATB1 expression is significantly up-regulated in liver fibrotic tissues from HBV chronic patients and HBV Tg mouse model, and knockdown of SATB1 in the liver significantly alleviates the fibrosis induced by $\mathrm{CCl} 4$ exposure in the HBV-Tg mouse model. Increased expression of SATB1 in hepatocytes enhances the activation and proliferation of hepatic stellate cells (HSCs) by secreting connective tissue growth factor (CTGF), Interleukin-6 (IL-6) and platelet derived growth factor-A (PDGF-AA). Their findings demonstrate that hepatic SATB1 upregulated by HBx exerts pro-fibrotic effects by paracrine activation of stellate cells in HBV-related fibrosis. Feng et al. [56] also investigated the significance of $\mathrm{HBx}$ in liver fibrosis during the progression of $\mathrm{HBV}$-associated liver diseases, by assessing the upregulated P4HA2 in a model of fibrotic liver tissues from HBV-Tg mice, and clinical samples of liver fibrosis and liver cirrhosis. Interestingly, they found that $\mathrm{HBx}$ accelerates the collagen deposition in liver fibrosis through modulation of miR-30e targeting P4HA2 mRNA. The results provide novel perspectives on how $\mathrm{HBx}$ promotes liver fibrosis during development of $\mathrm{HBV}$-associated liver diseases. In addition, Ahodantin et al. [55] examined whether $\mathrm{HBx}$ promotes liver fibrosis in full length (FL)- $\mathrm{HBx} \mathrm{Tg}$ mice treated with $\mathrm{CCl} 4$, and observed that FL-HBx expression alters hepatocyte proliferation and potentiates CCl4-induced liver fibrosis, with increasing expression of inflammatory cytokines (TNF$\alpha$, TGF- $\beta$ ) and proteins (Collagen1a, $\alpha$-Sma, PdgfR- $\beta$, MMP-13) involved in the epithelial mesenchymal transition (EMT), and severity of liver disease. These data suggest that HBx may be involved in liver fibrosis via different molecular signaling pathways each other in $\mathrm{CCl} 4$ treated $\mathrm{HBx}$ and $\mathrm{HBV} \mathrm{Tg}$ mice.

$\mathrm{HBx}$ induced oxidative stress may be involved in regulation of liver diseases, hepatic steatosis and liver cancer

Oxidative stress, an imbalance between the formation of ROS and antioxidant defense mechanisms, is well- documented to play a key role in pathological courses. Numerous studies using HBV-expressing cells as well as HBV-expressing mice, have verified that HBV infection induces oxidative stress. Oxidative stress and oxidative damage are also increased in patients with HBV infection [58-60]. Oxidative stress produce ROS that damages cellular molecules like lipids, proteins and DNA during chronic infection of HBV, ultimately resulting in the development of liver disease. Increased oxidative components or decreased antioxidants have been reported in acute or chronic HBV infections [61-64]. One study based on different cell models reports that HBV replication induces cellular ROS expression, thereby suggesting that HBV replication induces oxidative stress [65]. Of the proteins encoded by the HBV genome, $\mathrm{HBx}$ is a viral protein that plays a key role in oxidative stress, and is associated with the functioning of mitochondria, which is a major source of ROS. HBx, which are colocalized to mitochondria with a human voltagedependent anion channel (HVDAC3), alters its transmembrane potential [66]. $\mathrm{HBx}$ also down-regulates mitochondrial enzymes related to the electron transport in oxidative phosphorylation (complexes I, III, $\mathrm{IV}$, and V), sensitizes the mitochondrial membrane potential in a hepatoma cell line, and increases mitochondrial ROS and lipid peroxide production [67]. In addition, mitochondrially associated $\mathrm{HBx}$ activates transcription factors STAT-3 and NF- $\mathrm{KB}$, and stimulates the mitochondrial translocation of Raf-1 via oxidative stress, which is relevant to liver disease pathogenesis associated with hepatitis B viral infection $[17,68]$. HBx expression is also related with increased oxidative damage. It is reported that the C-terminal region of $\mathrm{HBx}$ is essential for mitochondrial DNA damage [69]. Consistently, Ren et al. measured the AP sites and $\gamma \mathrm{H} 2 \mathrm{AX}$ foci (a marker for DNA double strand breaks (DSB)) and reported that HBx plays a key role in $\mathrm{HBV}$-induced oxidative stress, and $\mathrm{HBx}$ expression causes the oxidatively induced DNA damage associated with ROS [65]. These data indicate that $\mathrm{HBx}$ expression is associated with oxidative stress and DNA damage.

As described above, mitochondrial dysfunction is a crucial pathophysiological factor in $\mathrm{HBx}$-expressing hepatoma cells [67]. This suggests that HBx-induced mitochondrial dysfunction could be involved in liver diseases. It has been reported that patients with nonalcoholic steatohepatitis (NASH) present ultrastructural mitochondrial alterations [70] and increased ROS production [71, 72]. Therefore, mitochondrial dysfunction may play a key role in steatosis and steatohepatitis, by impairing fatty liver homeostasis and inducing the overproduction of ROS, that in turn 
trigger lipid peroxidation, cytokines release and cell death [73]. In association with these, accumulation of fatty change and dysplasia induced in our young $\mathrm{HBx}$ $\mathrm{Tg}$ mice suggest that mitochondrial dysfunction induced by $\mathrm{HBx}$ expression increases the ROS generation, which may cause steatosis and inflammation in $\mathrm{HBx} \mathrm{Tg}$ mice. On maturing, liver cancer is induced in the $\mathrm{HBx} \mathrm{Tg}$ mice by continuous accumulation of severe fatty changes and dysplasia (Tables 2, 3). As reported, ROS generation is remarkably increased in livers of $\mathrm{HBx} \mathrm{Tg}$ mice at 4 weeks of age, compared with that of WT control mice [74]. The HBx-induced ROS promotes the Akt pathways via oxidized inactive PTEN in HBx Tg mice and HepG2-HBx cells [75]. In addition, we investigated in which stage of tumorigenesis Prx- $\mathrm{SO}_{3}$, a hyperoxidized form of Prx2 and Prx3, may increase in $\mathrm{HBx} \mathrm{Tg}$ mice. The expression of Prx$\mathrm{SO}_{3}$ is highly increased in $\mathrm{HCC}$ of $\mathrm{HBx} \mathrm{Tg}$ mice as compared to WT mice, as well as in dysplasia and hepatocellular adenoma (HCA) of $\mathrm{HBx} \mathrm{Tg}$ mice, while pAkt and c-myc expressions were increased from earlier stage of tumorigenesis (Fig. 1), suggesting more severe oxidative stress in HCC.

ROS are important factors in the development of hepatic fibrosis. However, there is no evidence that the HBx-induced ROS expressions are directly involved in liver fibrosis. Necrosis was observed in only a few of our $\mathrm{HBx} \mathrm{Tg}$ mice investigated (Tables 1, 2). Necrosis is followed by progressive fibrosis. As mentioned above, liver fibrosis in transgenic mice for HBV and HBx is induced by exposure to $\mathrm{CCl} 4$ [55-57]. $\mathrm{CCl} 4$ treatment is widely applied to produce liver fibrosis in normal mice and rats since this model most closely resembles clinical human liver cirrhosis among the different experimental models of liver fibrosis [76-78]. $\mathrm{CCl}_{4}$ treatment induces a profound elevation of ROS production and oxidative stress via the MAPK/NF- $\mathrm{B}$ pathway [79]. Taken together, the above results indicate that the $\mathrm{HBx}$-induced
ROS is probably involved in promoting liver fibrosis caused by $\mathrm{CCl} 4$ treatment in normal mice.

\section{Conclusions}

$\mathrm{HBx}$ Tg mice inducing $\mathrm{HCC}$ were generated by microinjecting the $\mathrm{X}$-gene construct with the HBV-X gene under authentic promoter. Histological phenotypes associated with hepatic tumorigenesis were different, depending on the strain of $\mathrm{HBx} \mathrm{Tg}$ mice, suggesting that genetic background affects phenotypes of $\mathrm{HBx} \mathrm{Tg}$ mice.

Lipid accumulation and fatty changes were increased in the livers of $\mathrm{HBx}-\mathrm{Tg}$ hybrid mice and the messenger RNA and protein levels of SREBP1 as well as PPAR $\gamma$ were also upregulated in $\mathrm{HBx} \mathrm{Tg}$ mice. These results suggest that HBx protein induces hepatic steatosis in mice.

The role of $\mathrm{HBx}$ in regulating glucose metabolism was investigated in $\mathrm{HBx}-\mathrm{Tg} \mathrm{B} 6$ mice and $\mathrm{HBx}-\mathrm{Tg} \mathrm{B} 6$ mice lacking iNOS. Gluconeogenic genes were more significantly expressed in the livers of $\mathrm{HBx}-\mathrm{Tg} \mathrm{B} 6$ mice. This resulted in hyperglycemia, by increasing glucose production.

HBx correlates with the development of fibrosis. Convincing evidence is the induction of liver fibrosis in transgenic mice for $\mathrm{HBV}$ and $\mathrm{HBx}$ treated by carbon tetrachloride (CCl4). However, there is no evidence that the $\mathrm{HBx}$ is directly involved in liver fibrosis. The result indicates that $\mathrm{HBx}$-induced ROS may be involved in promoting liver fibrosis induced by $\mathrm{CCl} 4$ treatment in normal mice.

ROS generation was remarkably increased in livers of $\mathrm{HBx}$ Tg young mice, suggesting that mitochondrial dysfunction induced by HBx expression increases the ROS generation, resulting in steatosis and inflammation.

Taken together, all the results indicate that $\mathrm{HBx}$ induced ROS plays a role in inducing and promoting hepatic fatty change, glucose metabolism, and HCC.

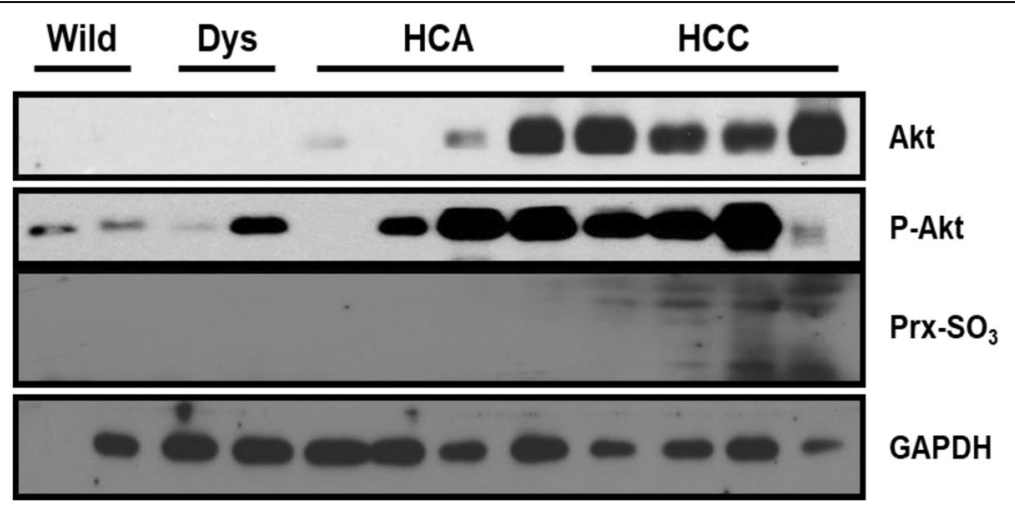

Fig. 1 Western blot result showing expression levels of Akt, p-Akt, and $\mathrm{Prx}_{-} \mathrm{SO}_{3}$ in livers of $\mathrm{HBx} \mathrm{Tg}$ mice. Glyceraldehyde 3-phosphate dehydrogenase (GAPDH) was used as a loading control. Wild; wild type, Dys; dysplasia, HCA; hepatocellular adenoma, HCC; hepatocellular carcinoma 


\section{Abbreviations}

CCl4: Carbon tetrachloride; CLD: Chronic liver disease; Cys): Cysteine; ECM: Extracellular matrix; $\mathrm{H}_{2} \mathrm{O}_{2}$ : Hydrogen peroxide; $\mathrm{HBV}$ : Hepatitis $\mathrm{B}$ virus; HBx: HBV X; HBx-Tg B6: HBx C57BL/6 Tg mice; HBx-Tg hybrid: HBx hybrid C57BL/6 X CBA) Tg mice; HCC: Hepatocellular carcinoma; HCV: Hepatitis C virus; iNOS: Inducible nitric oxide synthase; LXRa: Liver X receptor a; Prxs: Peroxiredoxins; ROS: Reactive oxygen species; SREBP1: Sterol regulatory element binding protein 1; Tg: Transgenic; WT: Wild type

\section{Acknowledgements}

The author thanks Drs. Kyung-Kwang Lee, Seishi Murakami, Hyung-Bae Moon, Hye-Jun Shin, Hye-Lin Ha, Young-Ho Park, Sun-Uk Kim, Jaehun Cheong, JinMan Kim and all the other lab members and collaborators greatly contributed to the research of HBx Tg mice. This research was supported by the KRIBB Research Initiative Program (KGM5382012) of Korea.

\section{Authors' contributions}

This study was designed, directed and coordinated by D.-Y.Y. The author(s) read and approved the final manuscript.

\section{Funding}

None.

\section{Availability of data and materials}

Not applicable.

\section{Competing interests}

The author declares no competing interests.

\section{Received: 1 December 2019 Accepted: 12 February 2020}

\section{Published online: 26 February 2020}

\section{References}

1. Liang TJ. Hepatitis B: the virus and disease. Hepatology. 2009;49(5 Suppl): S13-21.

2. Buti M, Rodriguez-Frias F, Jardi R, Esteban R. Hepatitis B virus genome variability and disease progression: the impact of pre-core mutants and HBV genotypes. J Clin Virol. 2005;34(Suppl 1):S79-82.

3. Zhang Z, Torii N, Hu Z, Jacob J, Liang TJ. X-deficient woodchuck hepatitis virus mutants behave like attenuated viruses and induce protective immunity in vivo. J Clin Invest. 2001;108(10):1523-31.

4. Cross JC, Wen P, Rutter WJ. Transactivation by hepatitis $B$ virus $X$ protein is promiscuous and dependent on mitogen-activated cellular serine/threonine kinases. Proc Natl Acad Sci U S A. 1993:90(17):8078-82.

5. Bouchard MJ, Schneider RJ. The enigmatic $X$ gene of hepatitis $B$ virus. J Virol. 2004;78(23):12725-34

6. Koike $K$, Moriya $K$, Yotsuyanagi $H$, lino $S$, Kurokawa K. Induction of cell cycle progression by hepatitis B virus HBx gene expression in quiescent mouse fibroblasts. J Clin Invest. 1994;94(1):44-9.

7. Sinn DH, Lee J, Goo J, Kim K, Gwak GY, Paik YH, et al. Hepatocellular carcinoma risk in chronic hepatitis B virus-infected compensated cirrhosis patients with low viral load. Hepatology. 2015;62(3):694-701.

8. Feitelson MA, Lee J. Hepatitis B virus integration, fragile sites, and hepatocarcinogenesis. Cancer Lett. 2007;252(2):157-70.

9. Wang $W L$, London $W T$, Lega L, Feitelson MA. HBXAg in the liver from carrier patients with chronic hepatitis and cirrhosis. Hepatology. 1991;14(1):29-37.

10. Tian Y, Yang W, Song J, Wu Y, Ni B. Hepatitis B virus X protein-induced aberrant epigenetic modifications contributing to human hepatocellular carcinoma pathogenesis. Mol Cell Biol. 2013;33(15):2810-6.

11. Belloni L, Pollicino T, De Nicola F, Guerrieri F, Raffa G, Fanciulli M, et al. Nuclear HBx binds the HBV minichromosome and modifies the epigenetic regulation of cccDNA function. Proc Natl Acad Sci U S A. 2009;106(47): 19975-9.

12. Gao W, Jia Z, Tian Y, Yang P, Sun H, Wang C, et al. HBx protein contributes to liver carcinogenesis by H3K4me3 modification through stabilizing WD repeat domain 5 protein. Hepatology. 2019.

13. Feitelson MA, Clayton MM. X antigen polypeptides in the sera of hepatitis $B$ virus-infected patients. Virology. 1990;177(1):367-71.

14. Feitelson MA, Clayton MM, Phimister B. Monoclonal antibodies raised to purified woodchuck hepatitis virus core antigen particles demonstrate $X$ antigen reactivity. Virology. 1990;177(1):357-66.
15. Lucifora J, Arzberger S, Durantel D, Belloni L, Strubin M, Levrero M, et al. Hepatitis $B$ virus $X$ protein is essential to initiate and maintain virus replication after infection. J Hepatol. 2011;55(5):996-1003.

16. Tsuge M, Hiraga N, Akiyama R, Tanaka S, Matsushita M, Mitsui F, et al. HBx protein is indispensable for development of viraemia in human hepatocyte chimeric mice. J Gen Virol. 2010;91(Pt 7):1854-64.

17. Chen J, Siddiqui A. Hepatitis B virus $X$ protein stimulates the mitochondrial translocation of Raf-1 via oxidative stress. J Virol. 2007;81(12):6757-60.

18. Cho HK, Cheong KJ, Kim HY, Cheong J. Endoplasmic reticulum stress induced by hepatitis $B$ virus $X$ protein enhances cyclo-oxygenase 2 expression via activating transcription factor 4. Biochem J. 2011;435(2):431-9.

19. Buechter DD. Free radicals and oxygen toxicity. Pharm Res. 1988;5(5):253-60.

20. Halliwell B. Oxygen and nitrogen are pro-carcinogens. Damage to DNA by reactive oxygen, chlorine and nitrogen species: measurement, mechanism and the effects of nutrition. Mutat Res. 1999:443(1-2):37-52.

21. Rhee SG, Kang SW, Chang TS, Jeong W, Kim K. Peroxiredoxin, a novel family of peroxidases. IUBMB Life. 2001;52(1-2):35-41.

22. Lu Y, Liu J, Lin C, Wang H, Jiang Y, Wang J, et al. Peroxiredoxin 2: a potential biomarker for early diagnosis of hepatitis $B$ virus related liver fibrosis identified by proteomic analysis of the plasma. BMC Gastroenterol. 2010;10:115.

23. Bae SH, Sung SH, Cho EJ, Lee SK, Lee HE, Woo HA, et al. Concerted action of sulfiredoxin and peroxiredoxin I protects against alcohol-induced oxidative injury in mouse liver. Hepatology. 2011;53(3):945-53.

24. Lu D, Wang W, Liu J, Qi L, Zhuang R, Zhuo J, et al. Peroxiredoxins in inflammatory liver diseases and ischemic/reperfusion injury in liver transplantation. Food Chem Toxicol. 2018;113:83-9.

25. Wang WL, London WT, Feitelson MA. Hepatitis $B \times$ antigen in hepatitis $B$ virus carrier patients with liver cancer. Cancer Res. 1991;51(18):4971-7.

26. Feitelson M. Pathogenesis of hepatitis B virus associated chronic liver disease. 2018

27. Twu JS, Schloemer RH. Transcriptional trans-activating function of hepatitis B virus. J Virol. 1987;61(11):3448-53.

28. Kim CM, Koike K, Saito I, Miyamura T, Jay G. HBx gene of hepatitis B virus induces liver cancer in transgenic mice. Nature. 1991;351(6324):317-20.

29. Billet $\mathrm{O}$, Grimber $\mathrm{G}$, Levrero M, Seye KA, Briand P, Joulin V. In vivo activity of the hepatitis B virus core promoter: tissue specificity and temporal regulation. J Virol. 1995;69(9):5912-6.

30. Lee TH, Finegold MJ, Shen RF, DeMayo JL, Woo SL, Butel JS. Hepatitis B virus transactivator $\mathrm{X}$ protein is not tumorigenic in transgenic mice. J Virol. 1990;64(12):5939-47.

31. Perfumo S, Amicone L, Colloca S, Giorgio M, Pozzi L, Tripodi M. Recognition efficiency of the hepatitis B virus polyadenylation signals is tissue specific in transgenic mice. J Virol. 1992;66(11):6819-23.

32. Reifenberg K, Lohler J, Pudollek HP, Schmitteckert E, Spindler G, Kock J, et al. Long-term expression of the hepatitis B virus core-e- and X-proteins does not cause pathologic changes in transgenic mice. J Hepatol. 1997;26(1):119-30

33. Yu DY, Moon HB, Son JK, Jeong S, Yu SL, Yoon H, et al. Incidence of hepatocellular carcinoma in transgenic mice expressing the hepatitis B virus X-protein. J Hepatol. 1999;31(1):123-32.

34. Wu BK, Li CC, Chen HJ, Chang JL, Jeng KS, Chou CK, et al. Blocking of G1/S transition and cell death in the regenerating liver of hepatitis $B$ virus $X$ protein transgenic mice. Biochem Biophys Res Commun. 2006;340(3):916-28.

35. Wang Y, Cui F, Lv Y, Li C, Xu X, Deng C, et al. HBsAg and HBx knocked into the p21 locus causes hepatocellular carcinoma in mice. Hepatology. 2004; 39(2):318-24.

36. Terradillos $\mathrm{O}$, Billet $\mathrm{O}$, Renard CA, Levy R, Molina T, Briand P, et al. The hepatitis $B$ virus $X$ gene potentiates $\mathrm{c}-$ myc-induced liver oncogenesis in transgenic mice. Oncogene. 1997;14(4):395-404.

37. Gordon A, McLean CA, Pedersen JS, Bailey MJ, Roberts SK. Hepatic steatosis in chronic hepatitis B and C: predictors, distribution and effect on fibrosis. J Hepatol. 2005;43(1):38-44.

38. Kim KH, Shin HJ, Kim K, Choi HM, Rhee SH, Moon HB, et al. Hepatitis B virus $X$ protein induces hepatic steatosis via transcriptional activation of SREBP1 and PPARgamma. Gastroenterology. 2007;132(5):1955-67.

39. Kim K, Kim KH, Kim HH, Cheong J. Hepatitis B virus X protein induces lipogenic transcription factor SREBP1 and fatty acid synthase through the activation of nuclear receptor LXRalpha. Biochem J. 2008;416(2):219-30.

40. Wang B, Li W, Fang H, Zhou H. Hepatitis B virus infection is not associated with fatty liver disease: evidence from a cohort study and functional analysis. Mol Med Rep. 2019;19(1):320-6. 
41. Wu YL, Peng XE, Zhu YB, Yan XL, Chen WN, Lin X. Hepatitis B virus X protein induces hepatic Steatosis by enhancing the expression of liver fatty acid binding protein. J Virol. 2016;90(4):1729-40.

42. Cheng AY, Kong AP, Wong WW, So WY, Chan HL, Ho CS, et al. Chronic hepatitis B viral infection independently predicts renal outcome in type 2 diabetic patients. Diabetologia. 2006;49(8):1777-84

43. Custro N, Carroccio A, Ganci A, Scafidi V, Campagna P, Di Prima L, et al. Glycemic homeostasis in chronic viral hepatitis and liver cirrhosis. Diabetes Metab. 2001;27(4 Pt 1):476-81.

44. Wang YY, Lin SY, Sheu WH, Liu PH, Tung KC. Obesity and diabetic hyperglycemia were associated with serum alanine aminotransferase activity in patients with hepatitis B infection. Metabolism. 2010;59(4):486-91

45. Majano PL, Garcia-Monzon C, Lopez-Cabrera M, Lara-Pezzi E, Fernandez-Ruiz E, Garcia-Iglesias C, et al. Inducible nitric oxide synthase expression in chronic viral hepatitis. Evidence for a virus-induced gene upregulation. J Clin Invest. 1998;101(7):1343-52.

46. Majano P, Lara-Pezzi E, Lopez-Cabrera M, Apolinario A, Moreno-Otero R, Garcia-Monzon C. Hepatitis B virus X protein transactivates inducible nitric oxide synthase gene promoter through the proximal nuclear factor kappaBbinding site: evidence that cytoplasmic location of $X$ protein is essential for gene transactivation. Hepatology. 2001;34(6):1218-24.

47. Lara-Pezzi E, Majano PL, Gomez-Gonzalo M, Garcia-Monzon C, MorenoOtero $\mathrm{R}$, Levrero $\mathrm{M}$, et al. The hepatitis B virus $\mathrm{X}$ protein up-regulates tumor necrosis factor alpha gene expression in hepatocytes. Hepatology. 1998; 28(4):1013-21.

48. Shin HJ, Park YH, Kim SU, Moon HB, Park DS, Han YH, et al. Hepatitis B virus $X$ protein regulates hepatic glucose homeostasis via activation of inducible nitric oxide synthase. J Biol Chem. 2011;286(34):29872-81.

49. Kim K, Kim KH, Cheong J. Hepatitis B virus X protein impairs hepatic insulin signaling through degradation of IRS1 and induction of SOCS3. PLoS One. 2010;5(3):e8649.

50. Bataller R, Brenner DA. Liver fibrosis. J Clin Invest. 2005;115(2):209-18.

51. Yang SL, Liu LP, Sun YF, Yang XR, Fan J, Ren JW, et al. Distinguished prognosis after hepatectomy of HBV-related hepatocellular carcinoma with or without cirrhosis: a long-term follow-up analysis. J Gastroenterol. 2016; 51(7):722-32.

52. Gutierrez-Reyes G, Gutierrez-Ruiz MC, Kershenobich D. Liver fibrosis and chronic viral hepatitis. Arch Med Res. 2007;38(6):644-51.

53. Lara-Pezzi E, Gomez-Gaviro MV, Galvez BG, Mira E, Iniguez MA, Fresno M, et al. The hepatitis $B$ virus $X$ protein promotes tumor cell invasion by inducing membrane-type matrix metalloproteinase-1 and cyclooxygenase-2 expression. J Clin Invest. 2002;110(12):1831-8.

54. Norton PA, Reis HM, Prince S, Larkin J, Pan J, Liu J, et al. Activation of fibronectin gene expression by hepatitis B virus $x$ antigen. J Viral Hepat. 2004;11(4):332-41.

55. Ahodantin J, Lekbaby B, Bou Nader M, Soussan P, Kremsdorf D. Hepatitis B virus $X$ protein enhances the development of liver fibrosis and the expression of genes associated with epithelial-mesenchymal transitions and tumor progenitor cells. Carcinogenesis. 2019. https://doi.org/10.1093/carcin/bgz109.

56. Feng GX, Li J, Yang Z, Zhang SQ, Liu YX, Zhang WY, et al. Hepatitis B virus X protein promotes the development of liver fibrosis and hepatoma through downregulation of miR-30e targeting P4HA2 mRNA. Oncogene. 2017;36(50): 6895-905.

57. Gong J, Tu W, Han J, He J, Liu J, Han P, et al. Hepatic SATB1 induces paracrine activation of hepatic stellate cells and is upregulated by $\mathrm{HBx}$. Sci Rep. 2016;6:37717.

58. Xu XM, Zhou XY, Li XY, Guo J, Wang HZ, Li Y, et al. Increased oxidative damage of RNA in liver injury caused by hepatitis B virus (HBV) infection. Free Radic Res. 2018;52(4):426-33.

59. Hsieh YH, Su IJ, Wang HC, Chang WW, Lei HY, Lai MD, et al. Pre-S mutant surface antigens in chronic hepatitis B virus infection induce oxidative stress and DNA damage. Carcinogenesis. 2004;25(10):2023-32.

60. Bhargava A, Khan S, Panwar H, Pathak N, Punde RP, Varshney S, et al. Occult hepatitis $B$ virus infection with low viremia induces DNA damage, apoptosis and oxidative stress in peripheral blood lymphocytes. Virus Res. 2010;153(1): $143-50$

61. Swietek K, Juszczyk J. Reduced glutathione concentration in erythrocytes of patients with acute and chronic viral hepatitis. J Viral Hepat. 1997;4(2):139-41

62. Chrobot AM, Szaflarska-Szczepanik A, Drewa G. Antioxidant defense in children with chronic viral hepatitis B and C. Med Sci Monit. 2000;6(4):713-8.
63. Demirdag K, Yilmaz S, Ozdarendeli A, Ozden M, Kalkan A, Kilic SS. Levels of plasma malondialdehyde and erythrocyte antioxidant enzyme activities in patients with chronic hepatitis B. Hepatogastroenterology. 2003;50(51):766-70.

64. Irshad M, Chaudhuri PS, Joshi YK. Superoxide dismutase and total anti-oxidant levels in various forms of liver diseases. Hepatol Res. 2002;23(3):178-84.

65. Ren JH, Chen X, Zhou L, Tao NN, Zhou HZ, Liu B, et al. Protective role of Sirtuin3 (SIRT3) in oxidative stress mediated by hepatitis B virus $X$ protein expression. PLoS One. 2016;11(3):e0150961.

66. Rahmani Z, Huh KW, Lasher R, Siddiqui A. Hepatitis B virus X protein colocalizes to mitochondria with a human voltage-dependent anion channel, HVDAC3, and alters its transmembrane potential. J Virol. 2000;74(6): 2840-6.

67. Lee $\mathrm{Yl}$, Hwang JM, Im JH, Lee YI, Kim NS, Kim DG, et al. Human hepatitis B virus-X protein alters mitochondrial function and physiology in human liver cells. J Biol Chem. 2004:279(15):15460-71.

68. Waris G, Huh KW, Siddiqui A. Mitochondrially associated hepatitis B virus X protein constitutively activates transcription factors STAT-3 and NF-kappa B via oxidative stress. Mol Cell Biol. 2001;21(22):7721-30.

69. Jung SY, Kim YJ. C-terminal region of HBx is crucial for mitochondrial DNA damage. Cancer Lett. 2013;331(1):76-83.

70. Caldwell SH, Swerdlow RH, Khan EM, lezzoni JC, Hespenheide EE, Parks JK, et al. Mitochondrial abnormalities in non-alcoholic steatohepatitis. J Hepatol. 1999;31(3):430-4.

71. Hensley K, Kotake Y, Sang H, Pye QN, Wallis GL, Kolker LM, et al. Dietary choline restriction causes complex I dysfunction and increased $\mathrm{H}(2) \mathrm{O}(2)$ generation in liver mitochondria. Carcinogenesis. 2000;21(5):983-9.

72. Perez-Carreras M, Del Hoyo P, Martin MA, Rubio JC, Martin A, Castellano G, et al. Defective hepatic mitochondrial respiratory chain in patients with nonalcoholic steatohepatitis. Hepatology. 2003;38(4):999-1007.

73. Begriche K, Igoudjil A, Pessayre D, Fromenty B. Mitochondrial dysfunction in NASH: causes, consequences and possible means to prevent it. Mitochondrion. 2006;6(1):1-28.

74. Ha HL, Shin HJ, Feitelson MA, Yu DY. Oxidative stress and antioxidants in hepatic pathogenesis. World J Gastroenterol. 2010;16(48):6035-43.

75. $\mathrm{Ha} \mathrm{HL}$, Yu DY. HBx-induced reactive oxygen species activates hepatocellular carcinogenesis via dysregulation of PTEN/Akt pathway. World J Gastroenterol. 2010;16(39):4932-7.

76. Sakaida I, Terai S, Yamamoto N, Aoyama K, Ishikawa T, Nishina H, et al. Transplantation of bone marrow cells reduces CCl4-induced liver fibrosis in mice. Hepatology. 2004;40(6):1304-11.

77. Chen Y, Zhao C, Liu X, Wu G, Zhong J, Zhao T, et al. Plumbagin ameliorates liver fibrosis via a ROS-mediated NF-small ka, CyrillicB signaling pathway in vitro and in vivo. Biomed Pharmacother. 2019;116:108923.

78. Geerts AM, Vanheule E, Praet M, Van Vlierberghe H, De Vos M, Colle I. Comparison of three research models of portal hypertension in mice: macroscopic, histological and portal pressure evaluation. Int J Exp Pathol. 2008:89(4):251-63.

79. Ma JQ, Ding J, Zhang L, Liu CM. Ursolic acid protects mouse liver against CCl4-induced oxidative stress and inflammation by the MAPK/NF-kappaB pathway. Environ Toxicol Pharmacol. 2014;37(3):975-83.

\section{Publisher's Note}

Springer Nature remains neutral with regard to jurisdictional claims in published maps and institutional affiliations.

Ready to submit your research? Choose BMC and benefit from:

- fast, convenient online submission

- thorough peer review by experienced researchers in your field

- rapid publication on acceptance

- support for research data, including large and complex data types

- gold Open Access which fosters wider collaboration and increased citations

- maximum visibility for your research: over $100 \mathrm{M}$ website views per year

At $\mathrm{BMC}$, research is always in progress.

Learn more biomedcentral.com/submission 